\title{
Growth hormone deficiency presenting under age 2
} years

\author{
S M HERBER AND R D G MILNER
}

Department of Paediatrics, University of Sheffield, and Sheffield Children's Hospital, Sheffield

SUMmaRY Twenty nine $(1 \cdot 8 \%)$ of a national cohort of 1600 patients with growth hormone deficiency presented before the age of 2 years. Sixteen of the 29 presented before 6 months of age-11 with symptomatic hypoglycaemia, four with failure to thrive, and one with obesity. Hypoglycaemia was persistent and difficult to control until growth hormone treatment was started. Ten of the 11 hypoglycaemic patients had multiple pituitary hormone deficiencies compared with two of the remaining five. Thirteen children presented between 6 months and 2 years of age; 12 had failure to thrive and one had spontaneous hypoglycaemia. Twelve of the 29 were boys and all but one of these had microgenitalia. Growth hormone deficiency should be considered in the differential diagnosis of infants presenting with refractory hypoglycaemia and in boys with failure to thrive and microgenitalia.

The presenting symptoms and signs of growth hormone deficiency in the older child are commonly short stature or a subnormal height velocity. These cardinal features are more difficult for the parent or doctor to appreciate in early life and this fact coupled with the infrequency of growth hormone deficiency leads to the possibility that the diagnosis is rarely considered in the infant or toddler. For this reason we thought it worthwhile to review the records of all children considered for growth hormone treatment in the United Kingdom since 1963 in order to identify the signs and symptoms in those presenting before the age of 2 years.

\section{Method}

The therapeutic use of growth hormone has been carefully monitored in the United Kingdom, initially by the Medical Research Council and latterly by the Health Services Human Growth Hormone Committee. A search was made of the records for all patients since 1963 in whom signs or symptoms of growth hormone deficiency were present before the age of 2 years. Patients accepted for growth hormone treatment who did not respond to this were excluded as was one boy who almost certainly has growth hormone deficiency but who suffers from a severe multisystem disorder, possibly due to an embryopathy, and who did not respond satisfactorily to treatment. This left 29 patients out of a total of 1600 . These 29 were subdivided according to age-those presenting before or after the age of 6 months-and diagnosis-isolated growth hormone deficiency or multiple pituitary hormone deficiences-as each factor influences the clinical features. The term isolated growth hormone deficiency was an operational diagnosis since many of the patients are still of prepubertal age and unequivocal evidence of normal gonadotrophin secretion has therefore not yet been established. In each case the patient's hospital records were examined by one of us (SMH) to assess the presenting features and subsequent response to hormone replacement treatment.

\section{Results (Table)}

Growth hormone deficiency presenting under 6 months of age. Sixteen ( 6 boys and 10 girls) of the 29 children presented under 6 months of age. Five (four girls and one boy) have isolated growth hormone deficiency. Eleven (five boys and 6 girls) have multiple hormone deficiencies; all are steroid deficient, 10 are thyroxine deficient as well, and one has diabetes insipidus. In addition, all 6 boys have microgenitalia (a micropenis with small or impalpable testes). None has as yet reached pubertal age, thus it is not possible to assess the incidence of gonadotrophin deficiency.

Nine of 11 children with multiple hormone 
Table Symptoms and signs of growth hormone $(G H)$ deficiency in children presenting before 6 months and between 6 months and 2 years of age

\begin{tabular}{|c|c|c|c|c|c|}
\hline Group & No & Hypoglycaemia & $\begin{array}{l}\text { Poor feeding/failure } \\
\text { to thrive }\end{array}$ & $\begin{array}{l}\text { Microgenitalia } \\
\text { (boys) }\end{array}$ & Obesity \\
\hline \multicolumn{6}{|l|}{ Under 6 months } \\
\hline (a) Multiple hormone deficiencies & 11 & 9 & 2 & $5($ of 5$)$ & \\
\hline (b) Isolated GH deficiency & 5 & 1 & 3 & 1 (of 1$)$ & 1 \\
\hline \multicolumn{6}{|l|}{ Six months to 2 years } \\
\hline (a) Multiple hormone deficiencies & 2 & 1 & 1 & & \\
\hline (b) Isolated GH deficiency & 11 & & 11 & $5($ of 6$)$ & \\
\hline
\end{tabular}

deficiencies presented with refractory hypoglycaemia as the principal feature; 8 did so in the first 24 hours of life and the 9th at 9 days of age. Only three children were of low birthweight and none of the mothers suffered from diabetes mellitus. All patients required intravenous glucose infusions to control their symptoms and four needed steroid treatment as well. Hypoglycaemia persisted in all children despite adequate caloric intake. This led to early assay of cortisol and thyroxine blood concentrations and consequently to early replacement treatment in 6 of the 9 but in the other three the diagnosis was delayed for 11 months, 18 months, and 4 years. Thyroxine and glucocorticoid treatment led to an improvement of symptoms in all cases but abolished symptoms in only one patient. The introduction of intramuscular growth hormone, usually 4 IU three times weekly but in three patients 2 IU daily, caused further improvement in all the children, although some are still prone to hypoglycaemia during periods of stress.

One patient aged 4 years died from hypoglycaemia in hospital, after admission for an attack of vomiting. He had been on growth hormone replacement treatment for 6 months. One of the other two patients with multiple hormone deficiencies had transient neonatal hypoglycaemia controlled by increasing oral feeds and the other had no recorded hypoglycaemia. Both fed poorly and had prolonged neonatal jaundice. Hypothyroidism was diagnosed on routine neonatal screening tests. Other hormone deficiencies were suspected in the boy because of microgenitalia and in the girl because of low maternal oestriol concentrations during pregnancy despite a normal sized fetus.

Cranial computed tomography has been performed on four of the 11 children; three were normal but the fourth child showed small optic nerves with an intact septum pellucidum. Six of the remaining 7 children have had skull radiographs; in one a shallow pituitary fossa was found but the others were normal. One of these 6 children, who has a midline cleft lip and palate, has a normal brain on ultrasound scan. Thyrotrophin releasing hormone stimulation tests suggested pituitary disease in one child with a normal computed tomogram and hypothalamic disease in one other. ${ }^{\prime}$ Two further children with normal skull radiographs had thyrotrophin releasing hormone stimulation tests-in one pituitary disease was suggested and in the other hypothalamic disease.

Three of the five children aged under 6 months with isolated growth hormone deficiency presented principally with failure to thrive and poor feeding. Failure to thrive in this context implied that the parents or referring doctor were most concerned about poor weight gain, although in all instances height velocity was also subnormal. Two had no elicitable symptoms of hypoglycaemia but the third was noted to be pale and sweaty in the mornings. The fourth child had symptomatic hypoglycaemia a few hours after birth followed by recurrent episodes of pallor, lethargy, and poor feeding. During a hospital admission at 9 weeks of age these signs were proved to be of hypoglycaemic origin. Growth hormone deficiency was diagnosed at 6 months of age after which replacement treatment with 2 IU growth hormone daily abolished the symptoms. Thyrotrophin releasing hormone stimulation test suggested hypothalamic disease in this child. The fifth child presented with excessive weight gain at 5 weeks of age despite being entirely breast fed. Concomitant short stature was noted. Growth hormone replacement treatment has increased the child's height but has not affected the obesity. Computed tomography was undertaken in this child and in the one with hypoglycaemia and was normal in both. Skull radiographs were normal in the other children.

Growth hormone deficiency presenting between 6 months and 2 years of age. Thirteen children ( 6 boys and 7 girls) presented initially between 6 months and 2 years of age. Two (both girls) have multiple hormone deficiencies and 11 have isolated growth hormone deficiency. Five of the 6 boys had 
microgenitalia at presentation but two have subsequently gone through normal puberty.

The first child with multiple hormone deficiencies presented with a hypoglycaemic convulsion at the age of 6 months. Failure to thrive and poor feeding ensued and she was prone to recurrent hypoglycaemia. Glucocorticoid and growth hormone replacement treatment have improved her symptoms considerably. Hypothyroidism developed at the age of 4 years, two years after starting growth hormone replacement treatment. She has a normal computed tomogram but a thyrotrophin releasing hormone stimulation test suggested pituitary disease. The other child had questionable neonatal hypoglycaemia which responded to early feeding. Feeding difficulties, irritability, and poor weight gain were noted thereafter, with ensuing hypotonia and developmental retardation. Growth hormone deficiency was diagnosed at the age of 2 years and after replacement treatment her behavioural disorders improved. Cortisol deficiency supervened two years later. Computed tomography showed an absent pituitary gland.

The 11 children with isolated growth hormone deficiency all presented primarily with failure to thrive. Only one child displayed possible spontaneous symptomatic hypoglycaemia having suffered several episodes of pallor and hypotension in hospital which were interpreted as adrenal crises. Two children developed symptomatic hypoglycaemia during an insulin tolerance test and one other was found to have an unrecordable fasting blood glucose concentration despite absence of symptoms. Two children had familial growth hormone deficiency and one other was already under supervision because the adrenogenital syndrome had been diagnosed.

\section{Discussion}

Congenital absence of the pituitary with associated hypoplasia of other endocrine organs was first described in $1956,{ }^{2}{ }^{3}$ since when there have been numerous case reports of congenital panhypopituitarism as a consequence of both pituitary ${ }^{4}$ and hypothalamic ${ }^{5}$ disease. The most common presentation of congenital panhypopituitarism seems to be hypoglycaemia that is refractory to conventional treatment and is associated with microgenitalia in boys. The condition has been associated with a high mortality and morbidity. In 1976 a resumé of 26 cases $^{6}$ in the published reports and in personal communication to the authors showed a mortality rate of two thirds, half occurring in the neonatal period. One of the 9 children in the present study that fall into this category has died, two are thought to be mentally subnormal but progress seems to have been satisfactory in the rest. The two children presenting over the age of 6 months with multiple hormone deficiencies are best regarded as variations of this syndrome, especially as hormone deficiencies, not obvious on initial assessment, have subsequently developed in both. One of these children is thought to be mentally subnormal. Two of these 11 children seem to have proved pituitary hypoplasia; in two others computed tomograms and thyrotrophin releasing hormone stimulation tests favour a hypothalamic aetiology; and in another two children these tests provide conflicting evidence.

Spontaneous hypoglycaemia was the principal feature in only one of the 16 children with isolated growth hormone deficiency, although three others seem to have been prone to spontaneous attacks and two displayed noticeable insulin sensitivity. One of the 16 children presented with excessive weight gain but all the others presented with either failure to thrive or feeding difficulties, or both.

The mechanism of hypoglycaemia in growth hormone deficiency has not been clearly defined, although it seems to be a common feature. ${ }^{7}$ Evidence favours increased peripheral uptake of glucose with associated impaired metabolism of free fatty acids for energy. ${ }^{8}$ No abnormalities of glycogen synthesis or hepatic glucose release have been reported and gluconeogenesis seems to be unaffected. ${ }^{9}$ Growth hormone replacement treatment causes an increase in blood glucose concentrations and a decrease in fat stores.

Microgenitalia in 11 of the 12 boys merits further comment. Initial sexual differentation in the male, in the presence of a normal gonad, is thought to be under the control of fetal human chorionic gonadotrophin. ${ }^{10}$ At the end of the first trimester fetal human chorionic gonadotrophin concentration declines and sexual maturation continues until term under the influence of fetal pituitary gonadotrophins. Growth hormone also seems to be involved in this process. ${ }^{11}$ As one of the patients in this study with microgenitalia at presentation has passed through normal puberty and as this has already been described, ${ }^{12}$ gonadotrophin deficiency is not necessarily always present in children with microgenitalia.

Symptomatic hypoglycaemia, particularly in the neonate, is associated with a high morbidity and must always carry a guarded prognosis; early optimal treatment is therefore essential. Growth hormone deficiency should be considered in any child with refractory hypoglycaemia, and microgenitalia is an important additional clue in boys. In older infants with failure to thrive the presence of microgenitalia should hasten the exclusion of pituitary disease as the cause. 
We thank Doctors N D Barnes, C G D Brook, P R Betts, J M H Buckler, C C Forsyth, T J French, D I Johnston, D A Price, M A Preece, P H W Rayner, D C L Savage and Professor J H Tanner whose kind assistance made this study possible. Financial support from the Trustees of the Former United Sheffield Hospitals is acknowledged.

\section{References}

${ }^{1}$ Milner RDG, Herber SM. Response to TRH in suspected hypopituitarism. Arch Dis Child 1983;58:195-7.

2 Blizzard RH, Alberts M. Hypopituitarism, hypoadrenalism and hypogonadism in the newborn infant. J Pediatr 1956:48:782-92.

${ }^{3}$ Mosier HD. Hypoplasia of the pituitary and adrenal cortex. J Pediatr 1956;48:633-9.

${ }^{4}$ Reid JD. Congenital absence of the pituitary gland. J Pediatr 1960;56:658-64

5 Lovinger RD, Kaplan SL, Grumbach MM. Congenital hypopituitarism associated with neonatal hypoglycacmia and microphallus: four cases secondary to hypothalamic hormone deficiences. J Pediatr 1975;87:1171-81.

${ }^{6}$ Cornblath H, Schwartz R. Hypoglycaemia in the neonate. In: Cornblath M. Schwartz R, eds. Disorders of carbohydrate metabolism in infancy. Philadelphia: WB Saunders, 1976: $177-80$.
7 Hopwood NJ, Forshaw PJ. Kenny FM. Drash AL. Hypoglycaemia in hypopituitary children. Am J Dis Child 1975:129:91826.

8 Aynsley-Green A. Hypoglycaemia in infants and children. J Clin Endocrinol Metab 1982:11:159-94.

${ }^{9}$ Haymond MW, Karl I. Weldon VV. Pagliari AS. The role of growth hormone and cortisol on glucose and gluconeogenic substratc regulation in fasting hypopituitary children. $J$ Clin Endocrinol Metab 1976:42:845-56.

${ }^{10}$ Clements JA, Reyes FI, Winter JSD, Faiman C. Studies on human sexual development. III. Fetal pituitary and serum and amniotic fluid concentrations of LH, CG and FSH. J Clin Endocrinol Metab 1976;42:9-19.

11 Zachmann M, Prader A. Anabolic and androgenic effect of testosterone in sexually immature boys and its dependency on growth hormone. J Clin Endocrinol Metab 1970;30:85-95.

12 Winter JSD, De Groot GW, Faiman C. Idiopathic sexual precocity in a boy with growth hormone prolactin and thyrotropin deficiencies. J Clin Endocrinol Metab 1974;39:356-63.

Correspondence to Dr S M Herber, Children's Hospital, Shefficld S10 $2 \mathrm{TH}$.

Received 21 February 1984 